\title{
An Appraisal of the Production Cycle Accounting Information System: Feat and Failure. The Case of Manufacturing Firms in Ethiopia
}

\author{
Yehualashet Getahun Ayele \\ School of Commerce, Addis Ababa University, PO box 1176, Addis Ababa, Ethiopia
}

The research is financed by the Author himself (Sponsoring information)

\section{Abstract}

Accounting Information System (AIS) continues to flourish, and organisations continue to become increasingly dependent upon their AIS to support business process and decision making. Should organizations do not give due attention to their AIS, the number of errors in stored data and the organisational impact of these errors is likely to increase. Inaccurate and incomplete data may adversely affect the competitive success of an organisation. Indeed, poor AIS can have significant social and business impacts.To make the study area more appealing, today's organisations are operating and competing in an information age. Information has become a key resource of most organisations, economies, and societies. Indeed, an organisation's basis for competition has changed from tangible products to intangible information; thereby highlighting the need for having well-developed Accounting Information System (AIS). Managers and other decision makers rely on the information provided to them when making decisions. Hence, the quality of the decision they make is a function of the quality of the information they get. This noticeable value of information marks the importance of having excellent accounting information system that enables decision makers to make informed decision. Simply put, in this information oriented era, managers and other decision makers rely heavily on information generated from the AIS employed by companies. Therefore, nowadays companies are paying good attention to their accounting information system which enables them to analyze their firm's performance. This growing importance of AIS has led the researcher to investigate the application and use of accounting information systems of selected manufacturing firms in Ethiopia.The design of the study is exploratory method of research design. This research design is found to be suitable because it addresses major objectives and research questions stated in the study satisfactorily. In the meanwhile, qualitative research approach was adopted to carry out this study. Moreover, because it was possible to obtain the information needed from all stakeholders of the nominated firms simultaneously, the time dimension of the study was cross-sectional. The study also gathered both primary and secondary data. Furthermore, the target population of this study is the entire permanent and temporary employees of the selected firms, out of which $25 \%$ of the employees were taken as a representative sample via a non-probability judgment sampling technique. Since the greatest expense or cost of manufacturing firms is their raw material cost, decision makers at all levels of the firms need to get well-timed reliable cost information for their sound decision making. Briefly, accounting information systems are pillars to the operation and management of every organization (predominantly manufacturing firms). Thus, owners, managers, regulatory bodies, and so on need the accounting information provided by their AIS to evaluate their firm's past performance and to map their future plans. To sum up, this study revealed that the role of accounting information systems to enhance the performance of manufacturing firms is undeniable; however; management perception, financial constraints, and unqualified human capital have hindered the establishment of sound accounting information systems in manufacturing firms in Ethiopia. Therefore, it can be concluded that the nominated manufacturing firms are not functioning at their full capacity as stakeholders are not getting the information they require for their decision making on account of the fragile and overlooked accounting information systems of the firms.

Keywords: Accounting Information System, Manufacturing Firms, Informed Decision Making, Company Performance

DOI: $10.7176 / \mathrm{IKM} / 10-2-01$

Publication date: February $29^{\text {th }} 2020$

\section{INTRODUCTION: THE ROLE OF AIS IN THE FRAMEWORK OF BUSINESS ACTIVITIES}

Our contemporary world is linked as never before due to advances in communication and information system on top of business/trade arrangements that have facilitated the exchange of goods and services. This growing interdependence has come to desire well-balanced and integrated Accounting Information System (AIS). Hence there is an obvious benefit from AIS in that via AIS firms in particular and nations in general may gain access to their tangible and intangible resources which they cannot easily access otherwise. In the light of this, a firm's particular interest is often best served through well designed and implemented AIS.

As pertinent and thoroughly integrated Accounting Information System signposts a milestone in the proper resource management system of a nation, in our modern world the need for Accounting Information System is 
alarmingly increasing. As such, systematically established/set Accounting Information System is vital for the national and global level anticipated business development and asset managements. In view of this, AIS is used to handle the maximum possible economic and business investigations information with the minimum possible cost and effort. To sum up, effective and profound AIS is one of the greatest inputs for the long run success of any organization.

In this study the Production Cycle (which is the transaction cycle chosen for this study) Accounting Information System of designated manufacturing firms is discussed. The researcher of this study believes that AIS is critical to organisations' success in today's highly competitive business environment. In the light of this, in this study the Production Cycle Accounting Information System (AIS) of selected manufacturing firms in Ethiopia is examined. In the meanwhile, it is also worth mentioning that AIS as a discipline within information systems requires well integrated accounting information. However, empirical evidences suggest that the configuration of accounting information is not as such trouble-free in AIS. This leads to unquestionable role of reflective AIS.

\section{BACKGROUND OF THE STUDY}

Many studies have emphasized the need to develop a well-established accounting information system (AIS). Yet many firms struggle to achieve AIS to date, there has been relatively few studies of AIS and in particular the factors that influence the AIS in manufacturing firms. Reviews of accounting information systems literature show that many studies have examined accounting information systems (AIS) design (Chong \& Chong 1997; Chenhall \& Langfield-Smith 1998; Mia \& Clarke 1999) particularly among manufacturing firms.

"The role and appraisal of AIS is one of the least researched and least discussed topics in professional journals and books focusing on business and economics" (Weller \& Weller, 2002, p.xiii). The role of AIS lies at the heart of contemporary business activities of all kind. However, there is no clearly defined and inimitable universal setup for the position of AIS in the framework of business activities and its level and/or quality of implementation is open to ambiguity and variation. Such variations in the performance of AIS exist from company to company as a result of company needs and the philosophy of company managers in the way that they delegate responsibility to others and want things to be done (Harvey \& Sheridan, 1995; Marshall, 1992; Mortimore, Sammons, Stoll, Lewis \& Ecob, 1989; Weller \& Weller,2002).

Various authors have argued that further research is needed to create a 'critical mass' of knowledge about the implementation level of AIS particularly in manufacturing firms. (Harvey \& Sheridan, 1995; Jayne, 1996; Ribbins, 1997; Southworth, 1994; Weller \& Weller, 2002).

The concept of Accounting Information System (AIS) has been discussed for many years, and premeditated AIS is deemed crucial in increasing firm performance. Yet few attempts have been made to investigate the use of AIS, especially in the context of manufacturing firms. This issue is important because results from previous studies suggest that many firms struggle to achieve properly implemented AIS. Therefore, this study identified the level of AIS usage in selected manufacturing firms in Ethiopia and then investigated the feat and failures of the firms as a result of their AIS practice. In particular, it spotlighted on the configuration of the requirements for accounting information (AIS requirements) and the capacity of accounting systems (AIS capacity) to generate the information, in the specific context of the production cycle in the designated firms. To sum up, this research succeeded to add to our current knowledge about implementation level of AIS in manufacturing firms, by focusing upon their production cycle. Besides, it also aspired to add to our knowledge about the ways in which Accounting Information System personnel team genuinely operates in the chosen manufacturing firms and the associated business outcomes (be it feat or failure) that emerge from the firms' AIS practice.

\section{STATEMENT OF THE PROBLEM}

Today's organisations are operating and competing in an information age. Information has become a key resource of most organisations, economies, and societies. Indeed, an organisation's basis for competition has changed from tangible products to intangible information; thereby highlighting the need for Accounting Information System (AIS). More and more organisations believe that properly handled accounting information is critical to their success (Wang et al., 1998). However, not many of them have turned this belief into effective action. Poor AIS can have significant social and business impacts (Strong, Lee \& Wang, 1997). There is strong evidence that AIS problems are becoming increasingly prevalent in practice (Redman 1998, Wand \& Wang, 1996). Most organisations have experienced the adverse effects of decisions made based on financial information of inferior AIS (Huang, Lee \& Wang, 1999). It is likely that some data stakeholders are not satisfied with the way information is managed and also the reliability of the information delivered in their organisations. In brief, AIS issues have become important for organisations that want to perform well, obtain competitive advantage, or even just survive in the $21^{\text {st }}$ century.

In particular, Accounting Information Systems (AIS) maintain and produce the data used by organisations to plan, evaluate, and diagnose the dynamics of operations and financial circumstances (Anthony, Reese \& 
Herrenstein, 1994). Providing and assuring relevant and reliable information to information users is an objective of accounting. With the advent of AIS, the traditional focus on the input and recording of data needs to be offset with recognition that the systems themselves may affect the quality of data (Fedorowicz \& Lee, 1998). Indeed, empirical evidence suggests that information relevance and reliability is problematic in AIS (Johnson, Leith, \& Neter, 1981). AIS deals with detecting the presence or absence of sound information management (Kaplan, Krishnan, Padman \& Peters, 1998).

Thus, knowledge of the position of up to date AIS undertakings in an organization will assist the organisation to improve its accounting information systems' management as finding the problem is half a solution. While many AIS studies have been conducted in various forms of firms at a range of accounting cycles, this study drew attention to the production cycle AIS practices of selected manufacturing firm in Ethiopia. It appears that there have been very few attempts to appraise the production cycle AIS of manufacturing firms, particularly in the Ethiopian context. Thus, there is a need for research to fill this gap.

Without a shadow of doubt the manufacturing sector lies at the heart of the "Growth and Transformation Plan, GTP" of our mother land Ethiopia. It appears that considering the enormous potentials of the manufacturing sector, and despite the acknowledgement of its immense contribution to sustainable economic development, its AIS still falls below expectation in many developing countries (Arinaitwe 2006). Manufacturing firms frequently lack well established AIS causing them to encounter high financing costs and high failure rates (Byron \& Friedlob 1984). The possible reasons for manufacturing firms' failures include among others 1) the poor information management and/or administrative skills of the owner/manager, 2) poor AIS, and 3) poor record-keeping, and etc. (Brooks, Collings \& Gonzales 1990). Poor record keeping and inefficient use of accounting information system are the major causes of failure in manufacturing firms according to Berryman (Berryman 1982 quoted in Siop 1997, Walton 2000, Wichmann 1983, World Bank 1978). The inefficient use of the accounting information systems to support their financial decision-making and the low quality and reliability of financial data are part of the main problems of manufacturing firms (Ubonratchat hanee University 2000).

Accounting information signals that decisions are needed, and provide information useful to making decisions (Gibson 1963 quoted in Thomas \& Evanson 1987; Report of the study group on the objectives of financial statements, American Institute of Certified Public Accountants, 1972 quoted in Lothian 1976). Accounting information system is used to assess the profitability of alternative courses of action, measure performance, and evaluate the position of enterprises in terms of profitability, liquidity, activity and leverage. It can be used to improve company performance, especially financial decisions. Even, for that matter, a company's survival is a function of its AIS-an inescapable fact facing most manufacturing firms in Ethiopia.

Altogether, it comes into view that little literature has discussed the production cycle AIS of manufacturing firms in Ethiopia. In contrast, AIS potentially concludes the feat and failure of a business in this dynamic information oriented business environment. Therefore, it is this fact of the challenge (problem) on the ground that led the researcher to come up with this study and strived to address this problem.

Research Problem: The production cycle accounting information system of manufacturing firms (MFs) in Ethiopia is hardly well organized and implemented as well as properly integrated to the AIS of other accounting cycles in the firms.

\section{RESEARCH QUESTIONS}

In order to explore the aforementioned research problem, this study largely focused on the following three major research questions:

RQ1. What factors affect the setup and implementation of AISs in the selected MFs?

RQ2. Are there any variations with regard to the perceptions of the importance of those factors that affect the setup of accounting information systems between:

- RQ2.1. different major AIS stakeholder groups of each firm?

- RQ2.2. the five accounting cycles of each of the firms?

RQ3. Does the actual performance level of the production cycle AIS of the firms affect their business performance?

\section{OBJECTIVES OF THE STUDY}

\subsection{GENERAL OBJECTIVE}

The general objective of this study is to examine the extent to which AIS is being practiced in selected MFs as per the theoretical argument of achieving relevant and reliable information to information users of all levels. Moreover, impact of accounting information systems on institutional performance shall be reviewed.

\subsection{SPECIFIC OBJECTIVES}

The following themes highlight the specific objectives of the study. 
To identify factors that affects the set up and implementation of AISs in selected MFs in Ethiopia.

To uncover the main weakness and strength of the AIS of the firms.

To scrutinize problems, if any, associated to the AIS strategies used by these firms.

To assess constraints related to the practical implementation of AIS in the firms.

To inspect the extent of AIS implementation in the selected MFs.

To appraise the scope to which all accounting cycles collaborate with the said firm's AIS.

\section{SIGNIFICANCES/BENEFITS OF THE STUDY}

AIS continues to flourish, and organisations continue to become increasingly dependent upon their AIS to support business process and decision making. Should organizations do not give due attention to their AIS, the number of errors in stored data and the organisational impact of these errors is likely to increase. Inaccurate and incomplete data may adversely affect the competitive success of an organisation. Indeed, poor AIS can have significant social and business impacts. In particular, there are consequences of poor AIS. For example, errors in an inventory database may cause managers to make decisions that generate overstock or under-stock conditions. This, as a result, can cause losses to an organisation and / or harm its reputation. This calls for the need to research the area (i.e. Accounting Information System).

Outcomes of this research will contribute to the body of knowledge in AIS, and it may benefit other researches into this area. For example, it can help arouse the awareness of stakeholders in AIS, and to make it possible to establish the linkage of the identified factors affecting the set up and implementation of the production cycle AIS of the firms. Thus, understanding how these factors affect organisations' AIS performance may be useful to practitioners. In brief, the results from this research are likely to help organisations' (particularly those of the selected MFs) top management, accountants, and IT managers obtain better understanding of AIS issues. Moreover, the findings of this study are likely to be used to upgrade the AIS of the firms, and all other manufacturing firms in Ethiopia of their dynamism. At last, but not least, the study also provided readers of its findings with insight of the production cycle AIS in a manufacturing firm.

\section{RESEARCH METHODOLOGY}

The design of the study is exploratory method of research design. This research design is found to be suitable because it addresses major objectives and research questions stated in the study satisfactorily. In the meanwhile, qualitative research approach was adopted to carry out this study. Moreover, because it was possible to obtain the information needed from all stakeholders of the firms simultaneously, the time dimension of the study was cross-sectional. The study gathered both primary and secondary data. Primary data was obtained through interviews and questionnaires to purposely selected employees of selected firms. The use of interviews was one of the successes of this study since it guaranteed confidentiality to the respondents; and thus they acted without any fear or embarrassment. Secondary data used includes censuses, organizational records and data collected through qualitative methodologies or qualitative research. On the other hand, the target population of this study is the entire permanent and temporary employees of the selected firms, out of which $25 \%$ of the employees were taken as a representative sample. Because the appraisal principally (of course not purely) targeted on those individuals who had experiences with accounting information system protocols in the firms, a non-probability judgment (that is, purposive) sampling technique has been adopted, in which the selection of the sample was based on the judgment about some appropriate characteristics required of the sample members. The producer of this study believes that this technique has allowed the researcher to select a sample to serve a specific purpose. This judgment sampling technique was chosen to safeguard the specific objective of the research, which is the investigation of the accounting information system protocol in the designated manufacturing firm in Ethiopia.

\section{MAJOR RESEARCH FINDINGS}

Some of the major findings of this study include the followings. In all of the manufacturing firms set aside for this study, most of the core activities of manufacturing firms are highly dependent on their financial information. Financial information, on the other hand, is best regulated and delivered by AISs. Thus, accounting information systems are vital to the operation and management of every manufacturing firm. Hence, firms become effective in their planning, operation and controlling of activities provided that a well-developed and integrated accounting information system is in place. This discovery of the study is in good agreement with empirical reviews which indicated that there exist a relationship between AIS and organizational performance. AIS is an effective decision-making tool for controlling and coordinating the activities of organizations. Most importantly, this study discovered that apt accounting information systems enhance organizations' ability to produce quality accounting information on a timely basis. The AIS also enables companies to ease the communication of financial and other relevant information to decision makers for informed decisions. Furthermore, this study also discovered that the setup and implementation of AISs are highly dependent the perception of firms' top 
management towards AIS and its use. Similarly, the capacity of the firms' human capital is another important factor that affects the setup and implementation of AISs in manufacturing firms. That is, the more educated/skilled the human capital of firms, the more likely AIS will be in place. To conclude, this study discovered that accounting information systems play crucial role in improving the efficiency and effectiveness of manufacturing firms. AIS enables manufacturing firms to track their financial information and provided reliable and well-timed accounting information to decision makers for their sound decisions.

\section{CONCLUSION AND RECOMMENDATION 9.1 CONCLUSION}

In the information era we are in, information (particularly financial information) is the most important resource of companies in general and manufacturing firms in particular. Since the greatest expense or cost of these firms is their raw material cost, decision makers at all levels of the firms need to get well-timed reliable cost information for their sound decision making. Simply put, accounting information systems are pillars to the operation and management of every organization (predominantly manufacturing firms). Thus, owners, managers, regulatory bodies, and so on need the accounting information provided by their AIS to evaluate their firm's past performance and to map their future plans.

In conclusion, one of the major discoveries of this study is that the role of properly implemented and used accounting information systems towards improving organizational effectiveness is clearly vibrant. Moreover, more than $94 \%$ of the respondents covered in this study believe that accounting information system is likely to make visible differences in the performance and profitability of firms if properly used by users of accounting information. Yet, in $67 \%$ of the firms set aside for this study the perception of managers to establishing good AIS is much below desires. Besides, quite significant number of the human force working in the AIS of the nominated firms lacks the fundamental technical knowledge of AIS. To sum up, this study revealed that the role of accounting information systems to enhance the performance of manufacturing firms is undeniable; however; management perception, financial constraints, and unqualified human capital have hindered the establishment of sound accounting information systems in manufacturing firms in Ethiopia. Therefore, it can be concluded that the nominated manufacturing firms are not functioning at their full capacity as stakeholders are not getting the information they require for their decision making on account of their fragile accounting information system.

\subsection{RECOMMENDATION}

Taking the research findings of this study into consideration, the researcher of this study recommends the following points for both future researchers and manufacturing firms' stakeholders in Ethiopia.

$\checkmark$ Stakeholders (or decision makers) of manufacturing firms need to realize that investment made on establishing or upgrading the AIS of the firms has to be encouraged provided that proper cost-benefit analysis is made.

$\checkmark$ Finally, the researcher recommends replication of this study in varies dynamisms/sectors.

\section{SELECTED FLOW CHARTS \& DIAGRAMS TAKEN FROM THE RESEARCH PAPER}

THE PRODUCTION PROCESS FLOW CHART OF THE DESIGNATED MFS:

Manufacturing firms make use of various raw materials as inputs which pass through and are subjected to profuse steps in the course of the production process. To start with, consider the following unembellished observed production cycle flow chart used in the designated MFs.

Can you visualize how the following practical production cycle of the factories functions as an input to the companies' production cycle Accounting Information System? 


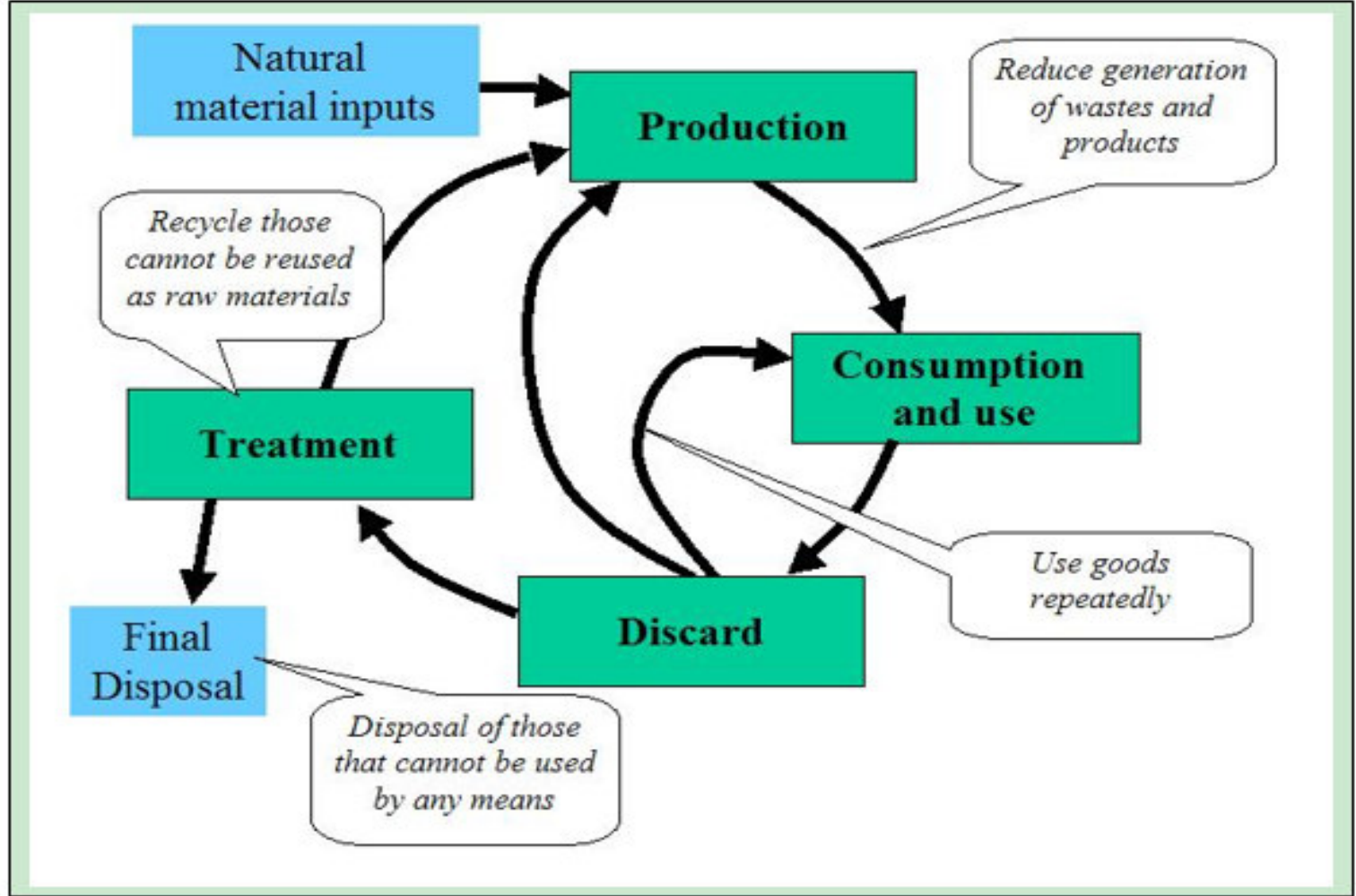

Figure-1: The production Process flow chart of the nominated MFs

The above flowchart is an impression of the Production Process/Cycle at the nominated manufacturing firms (MFs). The Production Cycle is a chronic set of business tricks and related statistics processing operations coupled with the manufacture of products. In understanding the flowchart it is important to look at its relationships and interactions with the other cycles. 
HOW THE PRODUCTION CYCLE INTERACTS WITH THE OTHER CYCLES:

Appreciate how the production cycle interacts with the other transaction cycles.

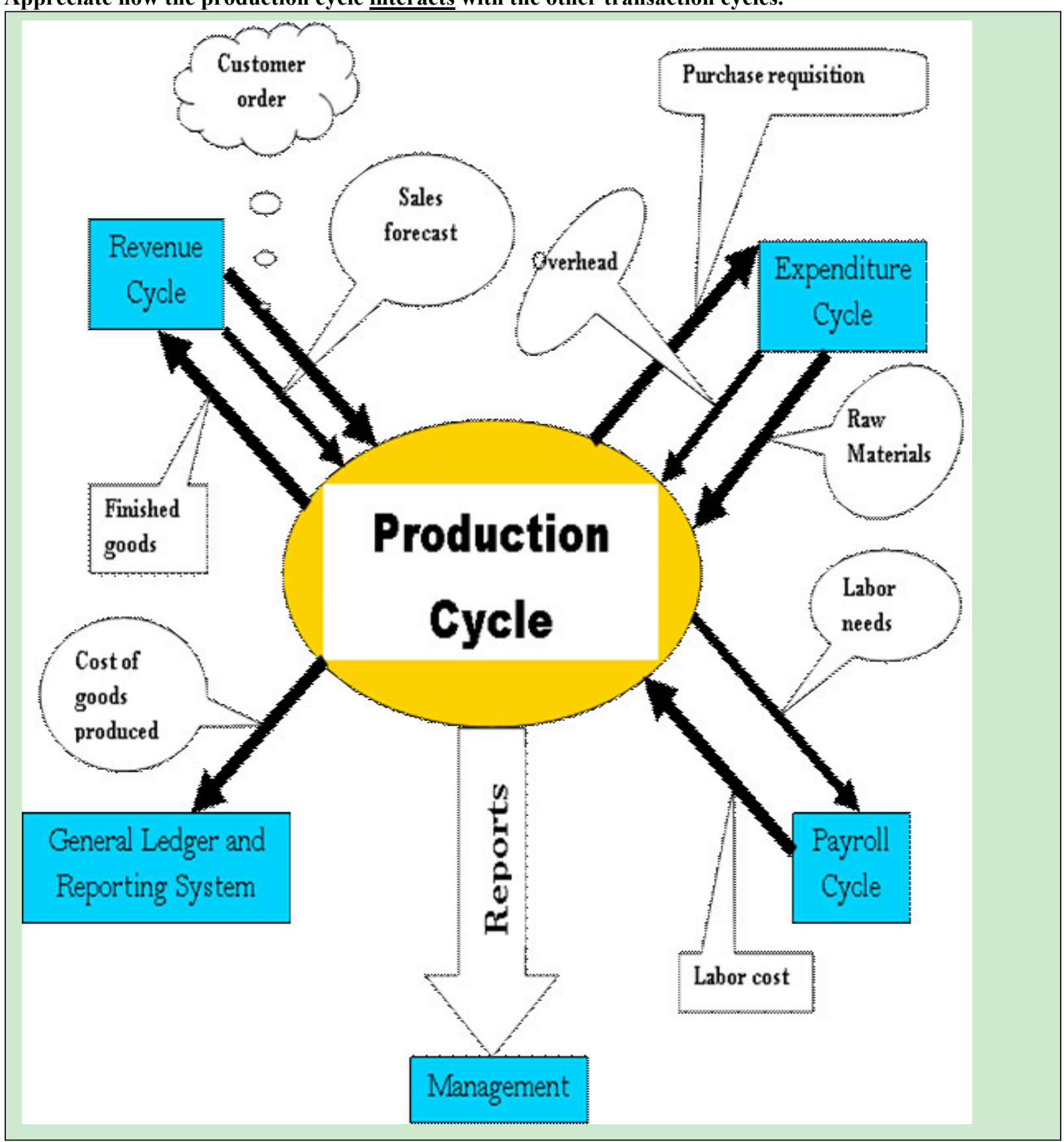

Figure-2: Context diagram of the production Cycle

Using the context diagram above (which, coincidentally, is typical to most manufacturing firms; and originated to be the actual/genuine context diagram in our chosen companies, MFs), the Production Cycle was shown as being linked to the Revenue Cycle by receiving customer orders and sales forecasts from the Revenue Cycle, and sending finished goods to the revenue cycle. It is linked to the Expenditure Cycle by sending purchase requisitions to order raw materials to the Expenditure Cycle, and the Expenditure Cycle then allocates overhead and raw materials costs to the Production Cycle. The Production Cycle is linked to the Human Resource/Payroll Cycle by requesting labor from HRP, which then allocates the labor costs to the Production Cycle. Management receives reports from the Production Cycle, which sends cost of goods produced information to the General Ledger and Reporting System. 
WHAT FACTORS AFFECT THE SETUP AND IMPLEMENTATION OF AISS IN THE SELECTED MFS?

\section{Factors that affect the setup \& implementation of AIS}

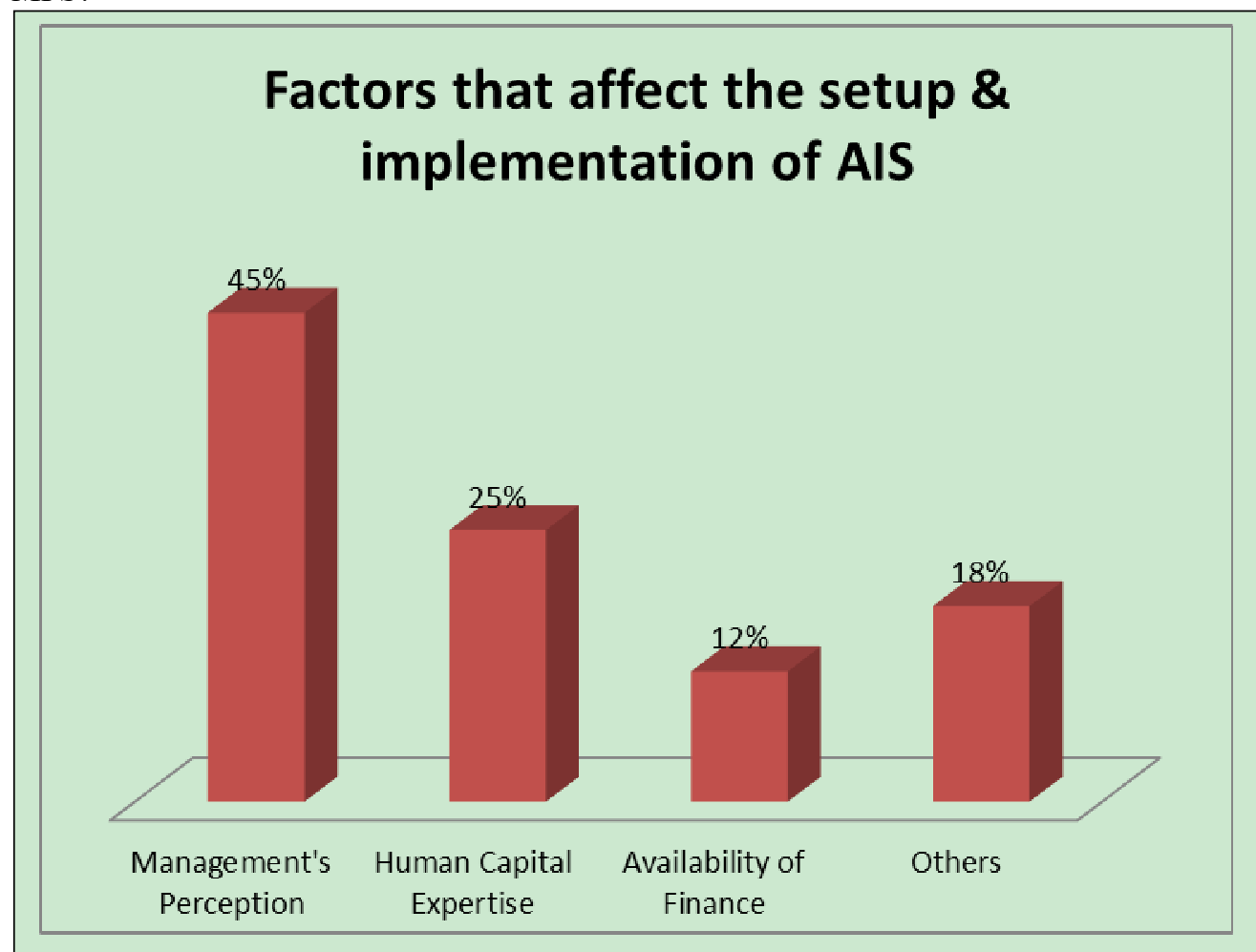

(Source: Own survey)

DOES THE ACTUAL PERFORMANCE LEVEL OF THE PRODUCTION CYCLE AIS OF THE FIRMS AFFECT THEIR OVERALL PERFORMANCE?

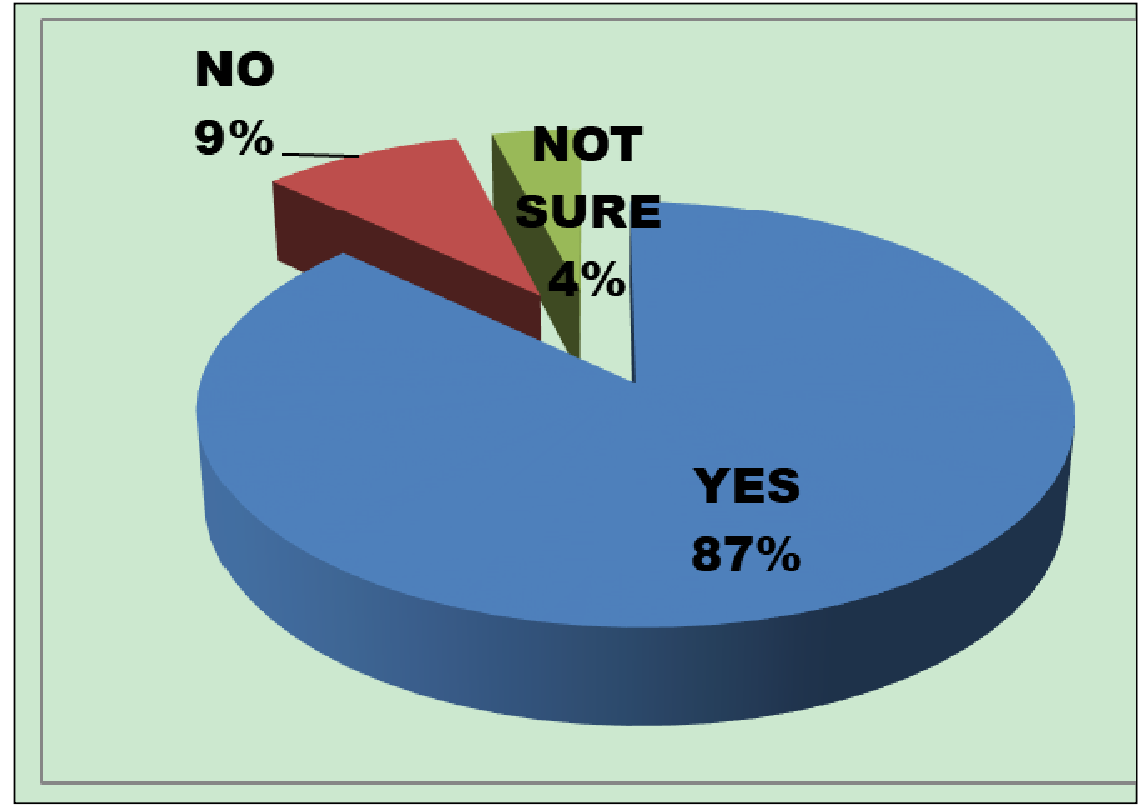

(Source: Own survey) 
HOW WOULD YOU RATE THE IMPACT OF AIS TOWARDS ORGANIZATIONAL EFFECTIVENESS?

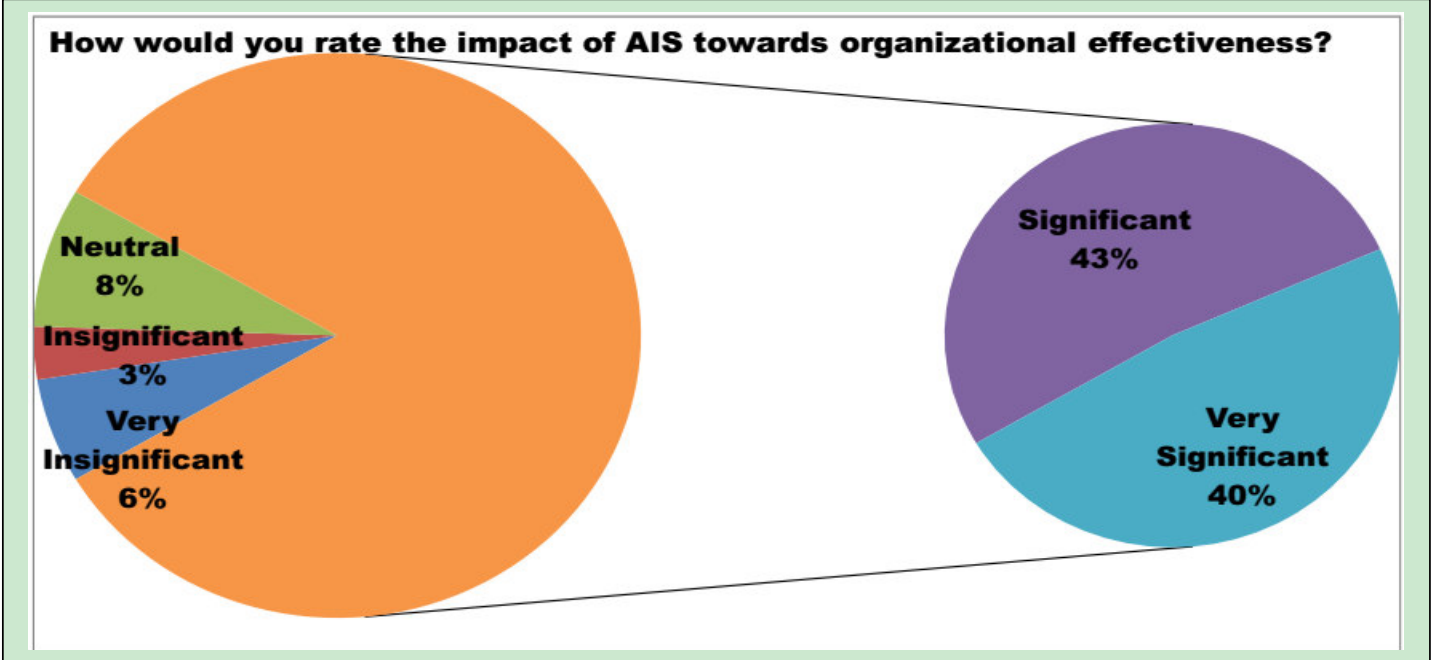

(Source: Own survey)

\section{References}

Chenhall, Robert H. and Langfield-Smith, Kim, Factors Influencing the Role of Management Accounting in the Development of Performance Measures within Organizational Change Programs. Management Accounting Research, Vol. 8, No. 4, December 1998. Available at SSRN: https://ssrn.com/abstract $=138473$

Chong, V., Chong, K., 1997. "Strategic choices, environmental uncertainty and SBU performance: A note on the intervening role of management accounting systems," Accounting and Business Research, Vol.27(4), pp. $268-76$

Fedorowicz, Jane \& Lee, Yang. (1998). Accounting Information Quality: Reconciling Hierarchical and Dimensional Contexts.

Kaplan, David \& Krishnan, Ramayya \& Padman, Rema \& Peters, James. (1998). Assessing Data Quality in Accouting Information Systems.. Commun. ACM. 41. 72-78. 10.1145/269012.269024.

Marshall, G. N., Wortman, C. B., Kusulas, J. W., Hervig, L. K., \& Vickers, R. R., Jr. (1992). Distinguishing optimism from pessimism: Relations to fundamental dimensions of mood and personality. Journal of Personality and Social Psychology, 62(6), 1067-1074. https://doi.org/10.1037/0022-3514.62.6.1067

Mia, L., Clarke, B., 1999. "Market competition, management accounting systems and business unit performance," Management Accounting Research, Vol.10(2)

Mortimore, Peter \& Sammons, Pam \& Stoll, Louise \& Lewis, David \& Ecob, Russell. (1989). A study of effective junior schools. International Journal of Educational Research. 13. 753-768. 10.1016/08830355(89)90026-8.

Sartorius, Kurt \& Eitzen, C. \& Kamala, P.. (2007). The design and implementation of activity-based costing $(\mathrm{ABC})$ : A South African survey research. Meditari Accountancy.

Wang, Y., D. Rind, C.R. Trepte, G.S. Kent, G.K. Yue, and K.M. Skeens, 1998: An empirical model study of the tropospheric meridional circulation based on SAGE II observations. J. Geophys. Res., 103, 13801-13818, doi:10.1029/98JD00204.

Weller, L.D. and Weller, S.J. (2002), The Assistant Principal: Essentials for Effective School Leadership, Corwin Press, Thousand Oaks, CA 